\title{
LA GUERRA COMO METÁFORA DE LA TRANSFORMACIÓN DE UN PAÍS
}

Federico Gonzalo Ferroggiaro es profesor en la Universidad Nacional de Rosario - Facultad de Humanidades y Artes y escritor. Escribió varios libros de cuentos y su última novela, Tetris, fue publicada por la UNR Editora en 2016. E-mail: fgferroggiaro@yahoo.com.ar

Cuando se califica a una novela de "histórica", tal afirmación oscila entre la presunción y la falacia. En primer lugar, porque ubica al lector ante cierta expectativa o inquietud que será defraudada porque, lo que se narra, en todos los casos, no ocurrió en realidad. Además, porque ni la más exhaustiva investigación sobre las fuentes, como la que, sin dudas, llevó adelante Marcelo Britos para componer A dónde van los caballos cuando mueren puede, al volverse lenguaje, convertirse en reflejo de la "Historia".

Una fiesta del lenguaje, $A$ dónde van los caballos... es una novela que consigue poner en movimiento varios tipos de relatos diferentes sin que esta multiplicidad perjudique o dificulte la lectura. Novela de guerra, pero de espaldas a cualquier épica grandilocuente, y en la cual el héroe se instala en las antípodas del paradigma del guerrero; novela de aventuras, tal vez más próxima al Cormac McCarthy de Todos los hermosos caballos, no tanto por la presencia de los equinos, sino por los símbolos que se recrean; novela de aprendizaje, a la vez, o para desaprender los clichés del discurso oficial; novela de viajes y peripecias en la que se recorre la geografía de una Argentina que experimenta las transformaciones del ingreso a la "modernidad". Novela que posee un indudable anclaje histórico, pero que puede prescindir del rigor historiográfico porque el relato se autonomiza de sus referentes para constituirse, plenamente, como ficción.

Luego de que, en 2013, recibiera el primer premio del Certamen Internacional de Literatura Sor Juana Inés de la Cruz y se editara en México, A dónde van los caballos cuando mиeren se publicó en 2015 bajo el sello Aurelia Rivera libros. En relación a su argumento, la narración se desarrolla durante la Guerra de la Triple Alianza (1864 1870), al término de la batalla de Curupaytí, cuando el médico Mariano de Orma escapa del campamento de Tuyutí hacia el sur, impulsado por el afán de huir del horror de la guerra y conservar sus últimos vestigios de humanidad. La deserción se suaviza con la excusa de cumplir la promesa formulada a un soldado moribundo: llevarle a sus sobrinos el caballo de ese hombre que va a morir. Bajando por el difuso mapa de aquella Argentina, en su travesía, Mariano de Orma luchará contra los peligros de la naturaleza y de la intemperie, pero también de la "civilización"; se adentrará en la vida oculta de un país que está atravesando un proceso de transformación y lo verá con otra mirada que se plasma en una prosa intensa y con gran despliegue poético.

La utilización de la guerra del Paraguay como trasfondo le imprime al texto una torsión política, a la vez que expone y condena los genocidios que tuvieron lugar en Argentina para atender las demandas británicas y cumplir con el proyecto de país de la generación liberal. De este modo queda propuesta, de alguna manera, una resignificación del concepto de "barbarie".

Es posible arriesgar, por último, que Marcelo Britos escribe contra la preeminencia de la estética de César Aira, y sus derivaciones, en la novelística argentina; que se aleja de esa discusión, o que la reactualiza posicionándose, como 
sucede con Zama de Di Benedetto, en un punto de fuga. O en un horizonte donde confluyen la historia y la (buena) literatura.

\section{Referências}

BRITOS, Marcelo. A dónde van los caballos cuando mueren. México DF: Secretaría de Educación del Gobierno del Estado de México, 2014.

BRITOS, Marcelo. A dónde van los caballos cuando mueren. Buenos Aires: Aurelia Rivero libros, 2015. 